\title{
A double blind placebo controlled comparison of verapamil, atenolol, and their combination in patients with chronic stable angina pectoris
}

\author{
IAIN N FINDLAY, KAY MACLEOD, GERARD GILLEN, ALEX T ELLIOTT, \\ THOMAS AITCHISON, * HENRY J DARGIE \\ From the Department of Cardiology, Western Infirmary Glasgow, and the ${ }^{\star}$ Department of Statistics, \\ University of Glasgow
}

SUMMARY The efficacy and effect on cardiac function of verapamil $120 \mathrm{mg}$ three times a day and atenolol $100 \mathrm{mg}$ once a day, singly and in combination, were evaluated in 15 patients with anginao pectoris. While they were on the combination treatment four patients withdrew from the study. Episodes of angina pectoris and glyceryl trinitrate consumption were significantly reduced only on the combination. On the combination only four patients developed evidence of ischaemia? during exercise compared with seven on verapamil and ten on atenolol. ST segment depression $\vec{\bullet}$ at peak exercise, assessed by 16 point precordial mapping, was reduced by all active treatments $\checkmark$ from 7.1 on placebo to $2.7,0.9$, and $0.6 \mathrm{~mm}$ on atenolol, verapamil, and the combination respectively. Mean left ventricular ejection fraction fell significantly from $60 \%$ on placebo to $53 \%$ on the combination but was unchanged on verapamil and atenolol.

Verapamil was an effective alternative to atenolol; the combination was the most effective treatment but was associated with a significant morbidity.

Although $\beta$ adrenoceptor blockers remain the mainstay for the treatment of effort related angina pectoris, in a considerable number of patients they may cause troublesome side effects, are only partially effective, or are relatively contraindicated.

Recently calcium antagonists have been introduced into the management of the various forms of angina pectoris including that related to effort. ${ }^{1-3}$ The differing and possibly complementary actions of the $\beta$ blockers and calcium antagonists raise the possibility that a combination of these two agents may have beneficial or detrimental interactions. ${ }^{4}$ While it is generally accepted that the combination of the calcium antagonist nifedipine and a $\beta$ blocker is safe in patients with normal ventricular function, ${ }^{5-7}$ caution has been advised with the combination of verapamil and a $\beta$ blocker because of the likely, and possibly detrimental, mutual potentiation of effects on cardiac conduction and contractility. ${ }^{189}$ We have evaluated the effects of verapamil and atenolol, singly and in combination, on cardiac function in patients with stable angina.

Requests for reprints to Dr Iain N Findlay, National Heart Hospital, Westmoreland Street, London W1M 8BA.

Accepted for publication 3 November 1986

\section{Patients and methods}

Fifteen patients (10 men) were recruited from the cardiology clinic of the Western Infirmary (table 1). All had chronic effort related angina pectoris with a stable pattern of symptoms for at least three monthsoand none had pain at rest. All had an unequivocally positive exercise test for myocardial ischaemiao ( $\geqslant 0.1 \mathrm{mV}$ ST segment depression occurring $80 \mathrm{~ms}$ after the $J$ point) at the end of a two week single으 blind placebo run in period during which all other $>$ antianginal medication was withdrawn.

We excluded patients with appreciable chronicn obstructive airways disease, severe hypertension (blood pressure $>170 / 110 \mathrm{~mm} \mathrm{Hg}$ off all treatment), $N$ myocardial infarction within the previous three $\omega$ months, peripheral vascular disease, previous con-을 gestive cardiac failure, or evidence of pronouncedo conduction abnormalities on the electrocardiogram. Coronary arteriography was carried out in most ${ }^{\text {? }}$ patients after the study was completed.

TRIAL DESIGN

There were four treatment periods each lasting three $\stackrel{\mathbb{D}}{\circ}$ weeks. They were placebo, verapamil $120 \mathrm{mg}$ three times a day, atenolol $100 \mathrm{mg}$ once a day, and the 
Table 1 Patient characteristics, exercise test (Bruce protocol), and coronary anatomy in patients with chronic stable angina

\begin{tabular}{|c|c|c|c|c|c|c|}
\hline & Age & Sex & $\begin{array}{l}\text { Previous } \\
\text { infarct }\end{array}$ & $\begin{array}{l}\text { Exercise } \\
\text { time (min) }\end{array}$ & Treatment & $\begin{array}{l}\text { Vessels with significant } \\
\text { stenosis ( }>50 \% \text { of } \\
\text { luminal diameter) }\end{array}$ \\
\hline $\begin{array}{r}1 \\
2 \\
3 \\
4 \\
5 \\
6 \\
7 \\
8 \\
9 \\
10 \\
11\end{array}$ & $\begin{array}{l}59 \\
55 \\
55 \\
53 \\
51 \\
57 \\
52 \\
62 \\
60 \\
58 \\
65\end{array}$ & $\begin{array}{l}\mathbf{M} \\
\mathbf{M} \\
\mathbf{F} \\
\mathbf{M} \\
\mathbf{M} \\
\mathbf{M} \\
\mathbf{F} \\
\mathbf{F} \\
\mathbf{M} \\
\mathbf{M}\end{array}$ & $\begin{array}{l}\overline{-} \\
\text { Inf } \\
\text { Inf } \\
\overline{-} \\
\overline{\text { n/t }} \text { Ant } \\
\overline{\text { Ant }}\end{array}$ & $\begin{array}{l}6 \cdot 0 \\
7 \cdot 3 \\
4 \cdot 3 \\
6 \cdot 0 \\
8 \cdot 3 \\
4 \cdot 3 \\
4 \cdot 0 \\
3 \cdot 0 \\
5 \cdot 0 \\
4 \cdot 0 \\
3 \cdot 0\end{array}$ & $\begin{array}{l}\text { Nifedipine } \\
\text { Atenolol/nifedipine } \\
\text { Oxprenolol } \\
\text { Triple therapy } \\
\text { Metoprolol } \\
\text { Nifedipine/nitrate } \\
\text { None } \\
\text { Atenolol } \\
\text { Atenolol/nifedipine } \\
\text { Pindolol/nitrate } \\
\text { Atenolol }\end{array}$ & $\begin{array}{l}\text { Not known } \\
\text { LAD, Cx, } 100 \% \text { RCA } \\
\text { LAD, Cx, 100\% RCA } \\
100 \% \text { Cx, RCA } \\
\text { LAD, Cx, } 100 \% \text { RCA } \\
\text { LAD, OM, } 100 \% \text { RCA } \\
\text { LAD, Cx, } 100 \% \text { RCA } \\
100 \% \text { LAD, } 100 \% \text { Cx, RCA } \\
\text { LAD, Cx, RCA } \\
100 \% \text { LAD, } 100 \% \text { RCA } \\
\text { Not known }\end{array}$ \\
\hline $\begin{array}{l}12 \\
13 \\
14 \\
15\end{array}$ & $\begin{array}{l}48 \\
44 \\
52 \\
54\end{array}$ & $\begin{array}{l}\mathbf{M} \\
\mathbf{F} \\
\mathbf{F} \\
\mathbf{M}\end{array}$ & $\begin{array}{l}z \\
z\end{array}$ & $\begin{array}{l}\text { Withdrar } \\
12 \cdot 0 \\
6 \cdot 0 \\
4 \cdot 0 \\
4 \cdot 0\end{array}$ & $\begin{array}{l}\text { from study } \\
\text { Metoprolol } \\
\text { None } \\
\text { Atenolol/nifedipine } \\
\text { None }\end{array}$ & $\begin{array}{l}\text { LAD, Cx, RCA } \\
\text { OM, 1st diag } \\
\text { Cx, } 100 \% \text { RCA } \\
\text { LAD, } 100 \% \text { Cx, RCA }\end{array}$ \\
\hline
\end{tabular}

Ant, anterior; Inf, inferior; $n / t$, non-transmural; LAD, left anterior descending; Cx, circumflex; RCA, right coronary artery; OM, obtuse marginal; lst diag, first diagonal. $100 \%=$ blocked.

combination. The order of administration was determined by a balanced latin square design, and the use of a double dummy technique ensured that all treatments were visually identical. At the end of each study period the following assessments were made.

\section{Subjective data}

Patients recorded the frequency of angina and consumption of glyceryl trinitrate on diary cards and each was asked to follow his or her normal daily routine throughout the trial. Moreover, patients were instructed to use glyceryl trinitrate for the treatment of acute attacks of angina but were asked to refrain from using it prophylactically.

Patients were asked about any important side effects and treatment preference.

\section{Objective data}

Heart rate and blood pressure-Heart rate and blood pressure were recorded after three minutes' recumbency and two minutes' standing and at the end of each exercise test.

Exercise testing: 16 point precordial electrocardiographic mapping-Patients exercised on an electronically braked bicycle ergometer. They started at $25 \mathrm{~W}$ and the workload was increased by $25 \mathrm{~W}$ every three minutes. Patients became familiar with the exercise test during three supine bicycle exercise tests performed while treatment was being withdrawn and before entry into the placebo run in period. Each patient's maximum workload was determined at the end of this period and thereafter he or she exercised to that workload. The number of points showing $\geqslant 1 \mathrm{~mm}$ planar ST segment depression (area of ischaemia) and the total ST segment depression were recorded immediately and at $1,3,5$, and 10 minutes after exercise. ${ }^{10}$ Heart rate and blood pressure were monitored throughout the test. 24 hour ambulatory electrocardiographic monitoringAmbulatory monitoring was carried out with the Medilog I system. The tapes were analysed for mean hourly heart rate and for abnormalities of cardiac rhythm and conduction. The PR interval was recorded from a standard 12 lead electrocardiogram taken immediately before ambulatory monitoring. Radionuclide ventriculography - Gated radionuclide ventriculography was carried out at rest and during the last two minutes of bicycle exercise. The blood pool was visualised after the patient's red blood cells had been labelled in vivo with $800 \mathrm{mBq}$ of technetium-99m. Scintigraphic images were obtained by means of an Ohio series 100 single crystal gamma camera fitted with a high resolution parallel hole collimator, interfaced with a Varian computer. ${ }^{5}$ In our department left ventricular ejection fraction obtained by radionuclide ventriculography correlated well with contrast angiography $(r=0.8 n=$ 32 ); intraobserver reproducibility was high ( $\mathbf{r}=$ 0.95 ) and the standard error of the estimate was $3 \%$. Drug and catecholamine concentrations-Plasma concentrations of verapamil and nor-verapamil were measured in blood samples collected 2-4 hours after the last dose. Plasma atenolol concentration was measured 6-8 hours after the last dose. ${ }^{11}{ }^{12}$ Plasma noradrenaline (an index of peripheral sympathetic activity) was measured after the patient had been recumbent for 15 minutes. ${ }^{13}$

\section{STATISTICAL ANALYSIS}

This was performed by repeated measures analysis of variance across the four treatments. A Bonferroni 
338

correction for multiple comparisons was applied to allow for the possibility of spurious differences generated by the use of multiple $t$ tests and an overall significance level of $5 \%$ was used. ${ }^{14}$ The interpretation of the results is shown in the appendix.

The work done to the onset of angina pectoris and ST depression was analysed by log rank analysis. ${ }^{15}$

\section{Results}

Four patients withdrew from the study and are not included in the results. The study was analysed for a possible order or crossover effect but this was not apparent.

\section{SUBJECTIVE}

Angina pectoris and glyceryl trinitrate consumption The mean frequency of angina pectoris was 30.0 , $19.9,16.8$, and 7.6 episodes on placebo, atenolol, verapamil, and the combination respectively; only on the combination treatment was this reduction significant. Mean glyceryl trinitrate consumption was $37.1,13.7,9.0$, and 5.9 tablets (all not significant). Patient number 10 experienced severe
Findlay, MacLeod, Gillen, Elliott, Aitchison, Dargie $\stackrel{\frac{\text { T }}{\top}}{\frac{T}{\Phi}}$ angina pectoris on placebo with over one hundred attacks many of which required two glyceryl tri- $\rightarrow$ nitrate tablets for the relief of pain. Removal of this outlier from the analysis considerably reduced the average placebo values and also the estimate of over-듬 all variability of glyceryl trinitrate consumption $\overline{\bar{c}}$ from \pm 8.9 to \pm 2.4 and frequency of angina pectoris $\Phi$ from \pm 4.3 to \pm 2.9 ; this reduction in variability leads to improved treatment comparisons (table 2). ${ }^{\infty}$ Overall the combination was the most effective. treatment in reducing both the frequency of angina $\overrightarrow{-}$ and glyceryl trinitrate consumption.

\section{OBJECTIVE}

Heart rate and blood pressure (tables 3 and 4)

Verapamil and atenolol given alone significantly re- $\dot{\omega}$ duced erect and supine heart rate but had no effect $\omega^{\circ}$ on systolic or diastolic blood pressure. Resting heart? rate was lowest on the combination but this was notsignificantly different from that on atenolol. The $\rightarrow$ combination reduced both erect and supine, systolic and diastolic, blood pressure.

All active treatments significantly reduced the heart rate during exercise. This was most pro-

Table 2 Mean episodes of angina pectoris and glyceryl trinitrate consumption during each three week treatment period (excluding patient 10 (see text))

\begin{tabular}{|c|c|c|c|c|c|c|c|}
\hline \multirow[b]{2}{*}{ Variable } & \multirow[b]{2}{*}{$F$ value } & \multirow[b]{2}{*}{ p value } & \multicolumn{5}{|c|}{ Treatment comparisons } \\
\hline & & & Placebo & Verapamil & Atenolol & Combination & Pooled SE \\
\hline Angina pectoris & $5 \cdot 4$ & $<0.005$ & $\overline{23.6}$ & $15 \cdot 2$ & $\overline{17 \cdot 7}$ & $\overline{7 \cdot 1}$ & 2.9 \\
\hline Glyceryl trinitrate & $5 \cdot 7$ & $<0.006$ & $\overline{18 \cdot 3}$ & $\overline{5 \cdot 8}$ & $\overline{10 \cdot 8}$ & $3 \cdot 9$ & $2 \cdot 4$ \\
\hline
\end{tabular}

There is a significant difference between variables that are not connected by a line.

Table 3 Mean heart rate $(H R)$, blood pressure $(B P)$, and rate pressure product $\times 100(R P P)$ at rest and at placebo run maximum exercise workload

\begin{tabular}{|c|c|c|c|c|c|c|c|}
\hline \multirow[b]{2}{*}{ Variable } & \multirow[b]{2}{*}{$F$ value } & \multirow[b]{2}{*}{$p$ value } & \multicolumn{5}{|c|}{ Treatment comparisons } \\
\hline & & & Placebo & Verapamil & Atenolol & Combination & Pooled SE \\
\hline Supine HR & $44 \cdot 0$ & $<0.001$ & $\overline{83}$ & $\overline{73}$ & $\overline{60}$ & $\overline{53}$ & $2 \cdot 0$ \\
\hline Standing HR & $48 \cdot 0$ & $<0.0001$ & $\overline{90}$ & $\overline{80}$ & $\overline{61}$ & $\overline{55}$ & $2 \cdot 2$ \\
\hline Maximum HR & $66 \cdot 0$ & $<0.0001$ & $\overline{121}$ & $\overline{107}$ & $\overline{91}$ & $\overline{77}$ & $2 \cdot 4$ \\
\hline Supine systolic BP & $10 \cdot 5$ & $<0.001$ & $\overline{136}$ & 139 & 138 & $\overline{122}$ & $2 \cdot 5$ \\
\hline Erect systọlic BP & $9 \cdot 6$ & $<0.001$ & 137 & 131 & $\overline{125}$ & 115 & $3 \cdot 0$ \\
\hline Supine diastolic BP & $9 \cdot 7$ & $<0.001$ & $\overline{90}$ & 87 & $\overline{88}$ & $\overline{74}$ & $2 \cdot 4$ \\
\hline Erect diastolic BP & $10 \cdot 8$ & $<0.001$ & $\overline{91}$ & 83 & $\overline{82}$ & $\overline{71}$ & $2 \cdot 5$ \\
\hline Exercise systolic BP & $14 \cdot 9$ & $<0.001$ & $\overline{173}$ & 165 & 166 & $\overline{148}$ & $2 \cdot 9$ \\
\hline Resting RPP & $39 \cdot 0$ & $<0.0001$ & $\overline{113}$ & $\overline{102}$ & $\overline{83}$ & $\overline{65}$ & $3 \cdot 6$ \\
\hline Exercise RPP & $51 \cdot 0$ & $<0.0001$ & $\overline{215}$ & $\overline{178}$ & $\overline{153}$ & $\overline{116}$ & $6 \cdot 3$ \\
\hline
\end{tabular}


Table 4 Rest and exercise heart rate at maximum workload achieved during placebo run in

\begin{tabular}{|c|c|c|c|c|c|c|c|c|}
\hline \multirow[b]{2}{*}{ Patient } & \multicolumn{4}{|c|}{ Resting heart rate } & \multicolumn{4}{|c|}{ Exercise heart rate } \\
\hline & $P$ & $V$ & $A$ & $C$ & $P$ & $V$ & $A$ & $C$ \\
\hline $\begin{array}{r}1 \\
2 \\
3 \\
4 \\
5 \\
6 \\
7 \\
8 \\
9 \\
10 \\
11\end{array}$ & $\begin{array}{r}100 \\
76 \\
75 \\
96 \\
88 \\
79 \\
62 \\
80 \\
104 \\
76 \\
72\end{array}$ & $\begin{array}{r}85 \\
60 \\
80 \\
74 \\
100 \\
64 \\
69 \\
58 \\
83 \\
60 \\
70\end{array}$ & $\begin{array}{l}65 \\
58 \\
60 \\
68 \\
85 \\
53 \\
54 \\
44 \\
68 \\
49 \\
53\end{array}$ & $\begin{array}{l}64 \\
39 \\
62 \\
56 \\
58 \\
56 \\
52 \\
45 \\
60 \\
38 \\
48\end{array}$ & $\begin{array}{r}130 \\
103 \\
126 \\
130 \\
142 \\
122 \\
90 \\
120 \\
142 \\
98 \\
110\end{array}$ & $\begin{array}{r}128 \\
98 \\
118 \\
110 \\
135 \\
102 \\
95 \\
100 \\
105 \\
101 \\
90\end{array}$ & $\begin{array}{r}92 \\
88 \\
98 \\
92 \\
115 \\
94 \\
70 \\
90 \\
98 \\
75 \\
88\end{array}$ & $\begin{array}{r}102 \\
60 \\
94 \\
73 \\
92 \\
86 \\
72 \\
74 \\
74 \\
57 \\
66\end{array}$ \\
\hline
\end{tabular}

$P$, placebo; V, verapamil; $A$, atenolol; $C$, combination.

nounced on the combination, when the mean achieved heart rate was only 77 beats per minutesignificantly lower than that on atenolol. Systolic blood pressure was lower during exercise only on the combination but the rise in blood pressure was similarly attenuated by all active treatments.

The rate pressure product was significantly reduced at rest and during exercise by all active treat- ments; the reduction was most marked on the combination.

16 point precordial electrocardiograpic mapping During exercise $11,6,3$, and 2 patients developed ST segment depression and $10,8,5$, and 3 developed angina on placebo, atenolol, verapamil, and the combination respectively. The work done to the onset of angina pectoris was significantly increased only on verapamil and the combination $(p<0.05$ and $p<0.01$ ); work done to the onset of ST segment depression was significantly improved on all active phases $(p<0.05, p<0.005$, and $p<0.001$ for atenolol, verapamil, and the combination respectively). On the combination seven patients showed no evidence of exercise induced ischaemia (ST depression or angina) compared with four on verapamil and one on atenolol.

Table 5 shows the area and sum of the ST segment depression immediately after exercise and during the 10 minute recovery period.

\section{Twenty four hour ambulatory electrocardiographic monitoring}

The figure shows the mean hourly heart rate during

Table 5 Mean area of ischaemia (positive points) and ST segment depression at peak exercise and over the 10 minute recovery period as assessed by 16 point precordial electrocardiographic mapping

\begin{tabular}{|c|c|c|c|c|c|c|c|}
\hline \multirow[b]{2}{*}{ Variable } & \multirow[b]{2}{*}{$F$ value } & \multirow[b]{2}{*}{$p$ value } & \multicolumn{5}{|c|}{ Treatment comparisons } \\
\hline & & & Placebo & Verapamil & Atenolol & Combination & Pooled SE \\
\hline $\begin{array}{l}\text { Peak exercise: } \\
\text { Area of ischaemia }\end{array}$ & $19 \cdot 3$ & $<0.001$ & $\overline{5 \cdot 2}$ & $\overline{0.7}$ & $2 \cdot 3$ & 0.4 & 0.5 \\
\hline ST depression & $15 \cdot 7$ & $<0.001$ & $\overline{7 \cdot 1}$ & $\overline{0.9}$ & $2 \cdot 7$ & $\overline{0.6}$ & 0.8 \\
\hline $\begin{array}{l}\text { Recovery: } \\
\text { Area of ischaemia }\end{array}$ & $14 \cdot 3$ & $<0.001$ & $\overline{9 \cdot 9}$ & $\overline{1.0}$ & 3.5 & 0.6 & $1 \cdot 1$ \\
\hline ST depression & $13 \cdot 0$ & $<0.001$ & $\overline{11 \cdot 3}$ & $\overline{1 \cdot 2}$ & $3 \cdot 6$ & $\overline{0.8}$ & 1.4 \\
\hline
\end{tabular}

There is a significant difference between variables that are not connected by a line.

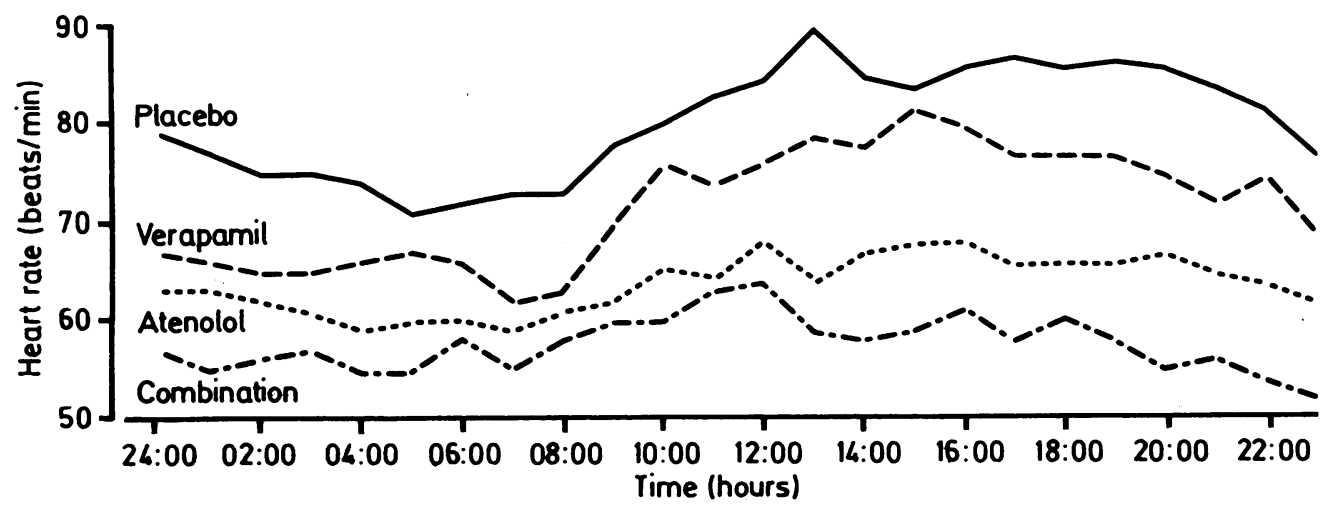

Figure Mean hourly heart rate recorded during 24 hour ambulatory electrocardiographic monitoring. 


\section{0}

ambulatory monitoring. All active treatments reduced the heart rate. The combination produced the greatest reduction. The mean PR interval varied from 0.17 to 0.19 seconds and there was no difference between the active treatments; it exceeded 0.2 seconds in 1,3 , and 4 patients on atenolol, verapamil, and the combination respectively; only on verapamil did it exceed 0.22 seconds $(0.26$ and 0.28 in patients 6 and 4 ).

\section{Radionuclide and ventriculography}

The mean (pooled SE) resting left ventricular ejection fraction was similar on placebo, verapamil, and atenolol at 60,57 , and 59 but fell significantly on the combination to 53 (3). During exercise the mean (pooled SE) left ventricular ejection fraction did not change significantly and was similar at $55,56,57$, and 53 (3) on placebo, verapamil, atenolol, and the combination respectively. On verapamil, atenolol, and the combination, 1,1 , and 4 patients respectively had a pronounced fall in left ventricular ejection fraction from placebo values $(>10 \%)$. In only one patient was this associated with an adverse reaction.

\section{Plasma concentrations of drugs and catecholamines}

Plasma concentrations of both atenolol and verapamil varied greatly during single and combination treatments and there were no significant differences in mean concentrations between single and combination treatments. Mean concentrations of verapamil in $\mu \mathrm{mol} / 1$ were 350 (range 127-600) and 445 (range 210-757), nor-verapamil 252 (range 77-376) and 324 (range 149-500), and atenolol 546 (range 130-1304) and 420 (range 100-867) on single and combination treatments respectively.

There was no consistent relation between verapamil and atenolol concentrations and subjective side effects or objective changes. Resting noradrenaline concentrations (normal range 0.8-3.0 nmol/l) were similar during all treatment periods: $2.48,2.90,2.81$, and $2.36(0.3) \mathrm{nmol} / 1$ (NS) for placebo, verapamil, atenolol, and the combination respectively.

\section{SIDE EFFECTS}

Adverse side effects were common during the combination treatment. Four patients (cases 12-15, table 1) withdrew from the study during the combination phase; one developed nodal rhythm, hypotension, and unstable angina requiring coronary artery vein graft surgery and three experienced severe dizziness and intolerable fatigue. These effects occurred within 24 hours of starting the combination treatment. The most serious adverse reaction that occurred in those completing the study was left

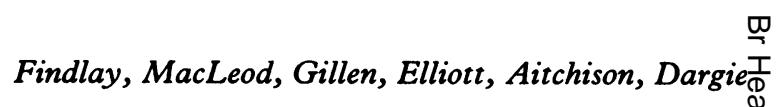
ventricular failure occurring in association with a sinus bradycardia of 38 beats per minute together ${ }^{c}$. with frequent periods of sinus arrest, one of which $\overrightarrow{\bar{F}}$ lasted four seconds (patient 10). This resolved promptly with intravenous diuretics and an increase in heart rate occurred. He continued on the combi- $\overline{\bar{c}}$. nation treatment with a diuretic. Radionuclide ven- $\widehat{\Phi}$ triculography was carried out three days later. Left ventricular ejection fraction was $43 \%$ compared ${ }^{\text {c) }}$ with $47 \%$ on placebo. Patient 2 experienced persis- $\vec{\circ}$ tent orthostatic dizziness, lethargy, and exertional $\overrightarrow{-}$ dyspnoea. His standing blood pressure fell from $\omega_{\sigma}^{\omega}$ $135 / 100 \mathrm{~mm} \mathrm{Hg}$ to $112 / 75,100 / 80$, and $95 / 60$ on placebo, verapamil, atenolol, and the combination of respectively. On the combination he had a resting. sinus bradycardia of 39 beats per minute which al- $\dot{\omega}$ ternated with periods of nodal rhythm. In addition, there were episodes of sinus arrest with pauses of up음 to 2.5 seconds before nodal escape occurred. Threeother patients experienced persistent fatigue or $\supset$ breathlessness (cases 4, 9, and 11). Although pa-ㅡ. tients 9 and 11 had the lowest resting ejection frac- $\vec{\theta}$ tion on placebo ( $46 \%$ and $47 \%$ respectively), only patient 2 had a considerable fall in resting ejection. fraction on the combination (from $64 \%$ to $49 \%$ ).

During ambulatory monitoring patient 9 showed similar but less frequent episodes of bradycardia as patient 2. Patient 11 developed considerable ankle oedema during combination treatment but there was $\cong$ no other clinical evidence of heart failure. Patient $8 \overrightarrow{\overrightarrow{0}}$ demonstrated sinus bradycardia on atenolol alone; 3 the lowest recorded rate being 38 beats per minute for five seconds.

No important problems were encountered during placebo or verapamil treatment. Constipation was troublesome in two patients on verapamil and on the combination; and another patient was constipated 3 . on atenolol. Five patients expressed a preference for verapamil as the most effective and acceptable treat- $₹$ ment, one for atenolol, two for the combination, ando three had no preference.

\section{Discussion}

Despite earlier equivocal studies verapamil in doses of 360 to $480 \mathrm{mg}$ per day is an effective antianginal agent. ${ }^{16-18}$ In this study verapamil markedly reduced exercise induced ischaemia and was at leasto as effective as atenolol despite producing a smallero reduction in the exercise rate pressure product. Sim $?$ ilar observations were reported when verapamil was ${ }^{0}$ compared with propranolol ${ }^{17-19}$ and these supporio the view that verapamil may have additional proper $\Omega$ ties, including favourable effects on coronary blood flow and ventricular diastolic function. ${ }^{20}$

Verapamil produced greater mean reductions in 
all objective and subjective indices of ischaemia than did atenolol but in general the combination was the most effective treatment. Although the reduction in the frequency of angina and in glyceryl trinitrate consumption was greatest during combination treatment, almost $50 \%$ of patients found that verapamil was the most acceptable treatment.

On combination treatment there was a pronounced reduction in the rate pressure product during exercise, principally through a lowering of heart rate, which was significantly greater than that on atenolol alone. Though reduction in exercise tachycardia is an important factor in lowering myocardial oxygen consumption, the considerable fall in heart rate that occurred in some of our patients may not be entirely beneficial. It may lead to such a reduction in cardiac output that lethargy and fatigue will occur during even moderate exertion and it is possible that the subjective side effects observed resulted from this effect.

The negative inotropic and chronotropic effects of short term verapamil treatment are offset by the reflex increase in sympathetic activity consequent upon the fall in systemic vascular resistance. ${ }^{21}$ When verapamil is given for longer increased sympathetic activity is unlikely to persist. ${ }^{22}$ In this study concentrations of plasma noradrenaline were similar (and normal) during all four treatment periods.

Resting left ventricular ejection fraction did not change on either of the active mono treatments, and though a significant fall has been reported on verapamil alone ${ }^{20}$ our findings resemble those of other investigators. ${ }^{391718}$ On the combination treatment, however, mean left ventricular ejection fraction fell significantly and left ventricular failure developed in one patient. The increase in heart size and the development of dyspnoea and cardiac failure noted in other studies ${ }^{189}$ emphasise the potential of the combination of verapamil and a $\beta$ blocker to depress myocardial contractility.

The left ventricular ejection fraction did not rise normally during exercise on any active treatment, despite the pronounced improvement in other indices of ischaemia. This accords with other studies of verapamil and has also been reported with propranolol. ${ }^{3918}$ None the less, in a previous study comparing nifedipine and atenolol, singly and in combination, left ventricular ejection fraction rose during exercise on nifedipine and on the combination but not on atenolol. ${ }^{5}$ This does not necessarily imply that this combination exerts a greater antiischaemia effect; rather it suggests that a greater reduction in left ventricular afterload occurs with nifedipine which is the most potent vasodilator among the existing calcium antagonists.

We observed a wide inter- and intraindividual variation in plasma concentrations of verapamil, with a range which resembled that reported in other studies. ${ }^{8171823}$ The probable lower effective plasma concentration of verapamil is around approximately $100 \mu \mathrm{mol} / 1$; in general plasma concentrations of verapamil above this bear little relation to the clinical effect. ${ }^{24}$ Verapamil undergoes rapid and extensive first pass metabolism, ${ }^{25}$ as do the lipophilic $\beta$ blockers such as propranolol, oxprenolol, and metoprolol. ${ }^{26} \mathrm{~A}$ pharmacokinetic interaction has been described between metoprolol and verapamil ${ }^{27}$ though Warrington et al did not demonstrate such an interaction between verapamil (50 $\mathrm{mg}$ three times a day) and propranolol, metoprolol, or atenolol. ${ }^{28}$ We postulated that atenolol, an hydrophilic cardioselective $\beta$ blocker that does not undergo appreciable hepatic metabolism and is excreted largely unchanged by the kidneys, ${ }^{26}$ would not be susceptible to such an interaction with verapamil. To our knowledge there are no reported data on the long term influence of $\beta$ blockade on verapamil concentrations in patients with coronary heart disease. We observed a modest rise in mean plasma concentrations of verapamil and nor-verapamil during combination treatment, which was not statistically significant.

Plasma concentrations of verapamil and atenolol taken from patient 10 during his admission with cardiac failure (12 hours post-dose) were 448 and $276 \mu \mathrm{mol} / 1$ respectively. Two days later $(2$ and 6 hours post-dosing), when the cardiac failure had resolved, the concentrations were 210 and $100 \mu \mathrm{mol} / 1$ respectively, the lowest recorded in any patient. It may be that relief of hepatic congestion and increased renal perfusion improved metabolism and excretion and thus produced lower concentrations of these agents. In general, however, there was no obvious relation between plasma concentrations and observed and reported adverse reactions. It would be difficult to demonstrate such a relation, given the reported wide variability of plasma concentrations within individuals even over a 24 hour period. ${ }^{29} 30$ Plasma concentrations in this study varied considerably during single and combination treatment. The absence of a consistent change during combination treatment does not suggest an important pharmacokinetic interaction; thus we conclude that the effects of this combination are principally the result of pharmacodynamic interaction.

Previously the safety and efficacy of combining verapamil with a $\beta$ blocker have been studied mainly with propranolol ${ }^{1892331}$ but major adverse effects have been reported during combination with other $\beta$ blockers. ${ }^{32} 33$ The reported frequency of haemodynamic and electrophysiological adverse reac- 
342

tions is variable; and in one review it was reported to be approximately $14 \%{ }^{34}$ These results were obtained in selected patients who had previously tolerated both types of drug, ${ }^{131}$ and in whom the dose was titrated to avoid adverse effects, ${ }^{18}$ and who had been studied in a previous trial ${ }^{1}$ or under hospital supervision. ${ }^{892331}$ Furthermore, in patients with poor effort capacity and depressed ventricular ejection fraction the frequency of adverse reactions rises significantly. ${ }^{31}$

Reports of the combination of verapamil and atenolol in patients with angina pectoris are sparse. In one study adverse reactions were not reported ${ }^{35}$ and in another open study mild left ventricular failure occurred in five of 31 patients in whom verapamil was added to atenolol to control resistant angina. ${ }^{36}$ In contrast, we experienced quite frequent (and in one case severe) adverse reactions on the combination that were not readily predictable even with detailed knowledge of cardiac function. Despite a fall in mean left ventricular ejection fraction on the combination, these side effects occurred principally in those in whom important bradycardia occurred.

Thus in this study we have used these two drugs at doses that might be considered maximal. Both are effective antianginal agents and it is likely that they will be used in combination in patients with angina. If they are we advise that the dose of the drug currently being taken should be reduced when a low dose of the other drug is added, and that the doses should be titrated to achieve the maximum tolerated effective dose. The presence of a previous myocardial infarction should alert the clinician to the possibility that the patient may tolerate combination treatment poorly. Any documented bradycardia is an absolute contraindication to such treatment.

\section{CONCLUSION}

Verapamil was an effective and well tolerated alternative to atenolol in patients whose exercise capacity was severely limited by chest pain. Since most patients were incompletely controlled on $\beta$ blockers before entry into the study, a selection bias against atenolol may have been a factor. The data do suggest, however, that it would be appropriate to change from a $\beta$ blocker to verapamil if the patient's symptoms are not controlled, before adding another antianginal agent. The combination of these agents further improved overall effectiveness; it has a place in certain patients but caution is required in its use, which must be closely supervised.

We thank Dr Rupinda Bhamra of the Poison's Unit at Guy's Hospital London for measuring plasma verapamil, nor-verapamil, and atenolol concentrations. Iain N Findlay was supported by a grant from the British Heart Foundation.
Findlay, MacLeod, Gillen, Elliott, Aitchison, Dargie $\underset{\frac{\square}{\Phi}}{\stackrel{\square}{\mathbb{T}}}$ Appendix

(a) The presentation of results gives an $\mathrm{F}$ value and $\overrightarrow{\vec{c}}$ corresponding $p$ value of the test of the hypothesis? that all four treatments give the same average $\frac{C}{0}$ response for that variable.

(b) The treatment comparisons $P$, placebo; V, vera- $\frac{\widehat{\sigma}}{\sigma}$ pamil; A, atenolol; and C, combination are given in a standard form to be interpreted as follows.

(i) $\overline{\mathbf{P}} \overline{\mathrm{V}} \overline{\mathrm{A} \mathrm{C}}$ means that there is no significant $\stackrel{\overline{ }}{\mathrm{C}}$ difference between the treatments $C$ and $A$ but both are different from $\mathrm{V}$ and also from $\mathrm{P}$ which itself is different from $\mathrm{V}$.

(ii) $\overline{\mathrm{PVA}} \overline{\mathrm{C}}$ means that the only significant $\dot{\mathrm{w}}_{\dot{\omega}}^{+}$ differences were between $C$ and each of the three treatments which themselves showed no significanto differences between themselves.

(iii) $\overline{\mathrm{P} \mathrm{VA} C}$ means that $\mathrm{C}$ and $\mathrm{A}$ were not? significantly different and that no separation $\overrightarrow{\vec{\bullet}}$ between $\mathrm{A}, \mathrm{V}$, and $\mathrm{P}$ could be found-that is theo only significant differences were between $\mathrm{C}$ and $\mathrm{V}^{-}$ and between $C$ and $P$.

Virtually all $F$ tests were referred to a $F^{330}$ distribution. The pooled standard error (SE) of the mean for any variable is given after the mean values.

\section{References}

1 Leon MB, Rosing DR, Bonow RO, Lipson LC, Epstein SE. Clinical efficacy of verapamil alone and combined with propranolol in treating patients with chronic stable angina pectoris. Am J Cardiol 1981;48:131-9.

2 Dargie HJ, Lynch PG, Krikler DM, Harris L, Krikler S. Nifedipine and propranolol: a beneficial drug interaction. $A m J_{\odot}$ Med 1981;71:676-82.

3 Johnson SM, Mauritson DR, Corbett JR, Woodward W, Will- 2 erson JT, Hillis LD. Double blind, randomised, placebo-윽 controlled comparison of propranolol and verapamil in the treatment of patients with stable angina pectoris. Am J Medo 1981;71:443-51.

4 Opie LH. Calcium antagonists. Mechanisms, therapeutic N indications and reservations. $Q J$ Med 1984;53:1-16.

5 Findlay IN, MacLeod K, Ford M, Gillen G, Elliott AT, DargieN HJ. Treatment of angina pectoris with nifedipine andN

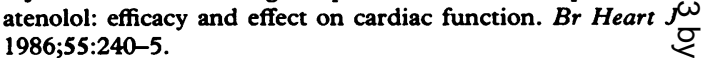

6 Tweddel AC, Beattie JM, Murray RG, Hutton I. The combinato tion of nifedipine and propranolol in the management of angina pectoris. Br J Clin Pharmacol 1981;12:229-33.

7 Rowland E, Razis P, Sugrue D, Krikler DM. Acute and chronic haemodynamic and electrophysiological effects of nifedipinein patients receiving atenolol. Br Heart $J$ 1983;50:383-9.

8 Winniford MD, Huxley RL, Hillis LD. Randomised, double blind comparison of propranolol alone and a propranolol- $\vec{\Phi}$ verapamil combination in patients with severe angina of effort. J Am Coll Cardiol 1983;1:492-8.

9 Johnstone DL, Gebhardt VA, Donald A, Kostuk WJ. Com- $\Omega$ 
parative effects of propranolol and verapamil alone and in combination on left ventricular function and volumes in patients with chronic exertional angina: a double blind, placebo controlled, randomised cross over study with radionuclide ventriculography. Circulation 1983;68:1280-9.

10 Fox K, Selwyn A, Shillingford J. Precordial electrocardiograph mapping after exercise in the diagnosis of coronary artery disease. Am J Cardiol 1979;43:541-6.

11 Bhamra RK, Thorley KJ, Vale JA, Holt DW. High performance liquid chromatographic measurement of atenolol: methodology and clinical applications. Ther Drug Monit 1983;5:313-8.

12 Cole SC, Flanagan RJ, Johnston A, Holt DW. Rapid high performance liquid chromatographic method for the measurement of verapamil and nor-verapamil in blood plasma or serum. J Chromatogr 1981;218:621-9.

13 Ball SG, Tree M, Morton JJ, Inglis GC, Fraser R. Circulating dopamine: its effect on the plasma concentrations of catecholamines, renin, angiotensin, aldosterone and vasopressin in the conscious dog. Clin Sci 1981;61:417-22.

14 Wallenstein S, Zucker CL. Fleiss JL. Some statistical methods useful in circulation research. Circ Res 1980;47:1-9.

15 Peto R, Pike MC, Armitage P, et al. Design and analysis of randomised clinical trials requiring prolonged observation of each patient. II Analysis and examples. $\mathrm{Br} J$ Cancer 1977;35:1-39.

16 Bala Subramanian V, Paramasivan R, Lahiri A, Raftery EB Verapamil in chronic stable angina: a controlled study with computerised multistage treadmill exercise. Lancet 1980;i:841-4.

17 Sadick NN, Tan ATH, Fletcher PJ, Morris J, Kelly DT. A double blind randomised trial of propranolol and verapamil in the treatment of effort angina. Circulation 1982;66:574-9.

18 Josephson MA, Hecht HS, Hopkins J, Guerrero J, Singh BM: Comparative effects of oral verapamil and propranolol on exercise induced myocardial ischaemia and energetics in patients with coronary artery disease: single blind placebo crossover evalution using radionuclide ventriculography. $\mathrm{Am}$ Heart $J$ 1982;103:978-85.

19 Arnman K, Ryden L. Comparison of metoprolol and verapamil in the treatment of angina pectoris. Am J Cardiol 1982;49:821-7.

20 Bonow RO, Leon MB, Rosing DR, et al. Effects of verapamil and propranolol on left ventricular systolic and diastolic filling in patients with coronary artery disease: radionuclide angiographic studies at rest and during exercise. Circulation 1982;65:1337-50.

21 Singh BN, Chew CYC, Josephson MA, Packer M. Pharmacologic and hemodynamic mechanisms underlying the antianginal actions of verapamil. Am J Cardiol 1982;50:886-93.

22 Laederach K, Gerber A, Weidmann P. Effect of calcium antagonists on blood pressure, catecholamines, renin, aldosterone and cardiovascular pressor responsiveness in normal and hypertensive man. In: Althaus U, Burckhardt D, Vogt E, eds.
Calcium-antagonismus/international symposium on calcium antagonism. Frankfurt/Main: Universimed. Verlag, 1984: 93-115.

23 Winniford MD, Fulton KL, Corbett JR, Croft $\mathrm{CH}$, Hillis LD. Propranolol-verapamil versus propranololnifedipine in severe angina pectoris of effort: a randomised, double blind, crossover study. Am J Cardiol 1985;55:281-5.

24 Frishman W, Kirsten E, Klein M, et al. Clinical relevance of verapamil plasma levels in stable angina pectoris. $\mathrm{Am} \mathrm{J} \mathrm{Car-}$ diol 1982;50:1180-4.

25 Hendry PD. Comparative pharmacology of calcium antagonists: nifedipine, verapamil and diltiazem. Am J Cardiol 1980;46:1047-58.

26 Cruikshank JM. The clinical importance of cardioselectivity and lipophilicity in beta blockers. Am Heart J 1980; 100:160-78.

27 McLean AJ, Knight R, Harrison PM, Harper RW. Clearance based oral drugs interaction between verapamil and metoprolol and comparison with atenolol. $\mathrm{Am} J$ Cardiol 1985;55:1628-9.

28 Warrington SJ, Holt D, Johnston A, Fitzsimons TJ. Pharmacokinetics and pharmacodynamics of verapamil in combination with atenolol, metoprolol and propranolol. $\mathrm{Br} \mathrm{J} \mathrm{Clin}$ Pharmacol 1984;17:37S-44S.

29 Eichelbaum M, Somogyi A. Verapamil distribution in health and the diseased state. In: Althaus U, Burckhardt D, Vogt E, eds. Calcium-antagonismus/international symposium on calcium antagonism. Frankfurt/Main: Universimed. Verlag, 1984:64-71.

30 Eichelbaum M. Clinical pharmacology of the calcium channel blockers. In: Lemberger L, Reidenberg MM, eds. Proceedings of the second world conference on clinical pharmacology and therapeutics. Bethesda, Maryland: American Society for Pharmacology and Experimental Therapeutics, 1984:774-87.

31 Subramanian B, Bowles MJ, Davies AB, Raftery EB. Combined therapy with verapamil and propranolol in angina pectoris. Am J Cardiol 1982;49:125-32.

32 Wayne VS, Harper RW, Laufer E, Federman J, Anderson ST, Pitt A. Adverse interaction between beta adrenergic blocking drugs and verapamil-report of three cases. Aust NZ J Med 1982;12:285-9.

33 Hutchison SJ, Lorimer AR, Lakhdar A, McAlpine SG. Beta blockers and verapamil: a cautionary tale. $\mathrm{Br}$ Med J 1984;289:659-60.

34 Leon MB, Rosing DR, Bonow RO, Epstein SE. Combination therapy with calcium-channel blockers and beta blockers for chronic stable angina pectoris. Am J Cardiol 1985; 55:69B-80B.

35 Lessem J. Combined therapy with Ca-antagonists and betaadrenergic combinations in chronic stable angina. Acta Med Scand 1982; suppl 681:83-90.

36 McGourty JC, Silas JH, Solomon SA. Tolerability of combined treatment with verapamil and beta blockers in angina resistant to monotherapy. Postgrad Med J 1985;61:229-32. 